\section{P-24 A CRITICAL EXPLORATION OF THE QUESTIONS ASKED AND DISCUSSED BY PALLIATIVE CARE PATIENTS}

Keith Morrison. Arthur Rank Hospice, Cambridge, UK

\subsection{6/bmjspcare-2017-hospice.51}

Background The use of an activity with palliative care patients called 'Blether' gave us the opportunity to consider the questions asked by them in the day therapy setting. The questions proffered and discussed were collected over 20 months. There were no comparable studies found that looked at the questions palliative care patients ask or an analysis of the issues and questions that appear to be of most concern.

Aim The aim of the study was to look at any common themes that occur for the palliative care patient and which they are prepared to consider in a group setting. This knowledge is helpful to those concerned in the pastoral care of patients, be it spiritual or psychological.

Methods All of the questions proffered and discussed (as voted for by the patient group) were collected. They were categorised and then counted. They were then considered from the perspective of pastoral theology.

Results In total 367 questions were generated and of them 54 were chosen to be discussed. Upon analysis of the data we discovered that the majority of questions discussed in 'Blether' were around issues of 'meaning'. A large number of patients proffered questions about God and Faith, it was not proportionally taken up as a subject for discussion. As well as 'meaning' other high scoring categories were 'Life issues', and 'Relationships'. It is hoped that the information gained is helpful in informing the work of all practitioners concerned with the spiritual and psychological care of palliative patients. Conclusions Issues of meaning and purpose are at the forefront of the minds of the palliative care patients and this is demonstrated when they are given the opportunity to ask a 'Spiritual' or 'Big question'. The benefits of this are that whilst anecdotal, patients appreciate this method and opportunity to stop and reflect. This work was part of an MA dissertation and has not as yet been published. 'Blether' (the activity referred to) was designed and delivered by Fire.Cloud and funded by NHS Education for Scotland.

\section{P-25 AFTER THE CONFERENCE... MAKING CHANGE HAPPEN}

Louise Moore, Linda Richmond, Hannah Sypula, Hannah Divall. Garden House Hospice Care, Letchworth, UK

\subsection{6/bmjspcare-2017-hospice.52}

Background Inspired by Miranda Quinney's Life Stories presented at Hospice UK conference, a unanimous decision was made to implement the project for patients. Awareness had grown through patient surveys and user groups that the need to be listened to and heard was strong but not acknowledged within a structured format. The Life Stories project known to enhance wellbeing and self-esteem allows the telling of an individual's experiences in a constructive and supportive environment. A project team looked at need, benefits, training and funding to make Story Telling a reality.

Aims Telling and recording of patient stories meets identified needs of out-patients which were not previously being fully met through planned interventions. Project presents patients with an opportunity to share significant stories from their life with skilled support of experienced facilitators, stories are heard, recorded and acknowledged. Funding was gained through the Burdett Trust, Foundation of Nursing Studies (FoNs). 'Patients First' Supporting nurse-led innovation workshops were attended. Staff training encouraged understanding of the workshop and selection of people to participate. Recruitment of experienced volunteers ensured stories would be documented and presented. Funding enabled release of staff, purchase of folders, props for prompting stories and further project development.

Results Patients' positive feedback demonstrates the workshop's benefit. Impact was particularly significant for a gentleman registered deaf. An interpreter was funded which opened up a new opportunity for the patient. Three courses have run attended by 16 people. Identified themes such as celebrations, home and travel have inspired anecdotes, words, dreams and reminiscence.

Conclusion The story began at conference, a new service for patients is successfully running. It is hoped that sharing this work will inspire others to take learning and put it into action to create service improvements.

\section{P-26 LIFE REVIEW OF HOSPICE PATIENTS BY VOLUNTEER JOURNALISTS}

Barbara Altounyan . The Hospice Biographers, London, UK

10.1136/bmjspcare-2017-hospice.53

Background Many bereaved people regret not capturing the voice and life story of loved ones who have died. Equally, being interviewed about their life is known to be therapeutic for the dying person and is a key strategy to underpin dignity. (Chochinov 2002)

Aims The new charity, The Hospice Biographers, will train journalists to interview hospice patients, in a systematic and sensitive way, to capture the voice and life story as a precious audio legacy for the next generation. Journalists are capable and incisive interviewers, and ideally suited. Over the next five years the aim is to record patients at 200 hospices across the UK so that families will still be able to hear the voice and stories long after their relative has died.

Method Hospices are invited to recommend journalists they already know and trust (or their own Communications staff) to volunteer for training by The Hospice Biographer team in clusters of five or six hospices per region. In each regional group, one hospice will host the training. The training course includes practical technical support, open interviewing techniques, privacy and confidentiality, emotional resilience, safeguarding and hospice regulation. Each hospice will then be supplied with a bespoke audio recorder specifically designed for use by Hospice Biographers. A pilot training course for six hospices and 12 journalists in the West Midlands was completed in May 2017 and has been evaluated via a structured questionnaire.

Results Lessons from the pilot included comments on the scope of training and the need for more practical instruction in the use of the recorder.

Next Steps A nationwide hospice road trip has confirmed huge interest in the project! A further five hospices and 10 journalists will be trained in October. Capacity planning and grant applications are in now in progress to support national rollout. 